\title{
Understanding Variation in the Practice of Employee Discipline
}

\author{
The Perspective of the First-Line Supervisor
}

\author{
JAVIER F. PAGAN \\ University of Puerto Rico
}

AIMEE L. FRANKLIN

The University of Oklahoma

\begin{abstract}
First-line supervisors' responses to employee-related problems can vary widely from one supervisor to another. Assuming fair and consistent disciplinary activity is valued by organizations, then discovery of the factors causing supervisors to respond differently to similar situations is a valuable activity. Using a case study approach for four organizations in Puerto Rico, this article explores how factors such as sector, union presence, and managerial and human resource department support influence the choice of a discipline strategy. When present, some of these factors were found to encourage supervisors to comply with formal disciplinary policy. Organizations can use these findings to assess the degree to which there is consistency in these factors and take strategic action to assure that first-line supervisors receive clear and consistent signals regarding appropriate disciplinary strategies.
\end{abstract}

Keywords: employee discipline; unions; first-line supervisors; discipline strategies; public/private sector comparisons; supervisor behaviors

Gor many organizations the question of how to deal with employee perfor-1 mance problems such as tardiness and absenteeism is one that first-line supervisors continually face. Individual supervisors employ different techniques, sometimes actions outside those in the organization's formal disciplinary policy. Within one organization we found that many supervisors "coach the employee and give additional opportunities for changing unacceptable behaviors," noting that human resource policy allows this approach. Other supervisors favored applying a 3-day suspension, claiming this was also "consistent with company discipline policy." A third group of supervisors simply

Review of Public Personnel Administration, Vol. 23, No. 1 March 2003 61-77

DOI: $10.1177 / 0734371 X 02250113$

(C) 2003 Sage Publications 
chose to do nothing, claiming that they are "more interested in productivity rather than measuring time." Similarly, inconsistent actions by first-line supervisors occurred in other organizations, as one supervisor described:

When I take disciplinary actions, they [the employee] realize they've done something wrong. First, I talk with them and then I write a warning letter or two. If things don't change, then I can still file for termination. Other supervisors will not do this, and will instead "look the other way."

At a third organization, a common response was to "barter the lemon" [an unproductive employee] to another supervisor, as this quote describes:

We have encountered many inefficient employees who simply don't make the grade, and we have tried getting rid of them, or even demoting them. But to no avail. So we say "OK," if this person doesn't work well here, let's try putting him or her there [another division]. We have done that on several occasions.

As these vignettes suggest, actions taken in response to employee-related problems can vary widely from one supervisor to another. In some situations the formal disciplinary policies and procedures are observed; in others the supervisor may choose from a variety of informal strategies for managing the problem employee. According to Bellizzi and Hasty (2000):

The severity of the discipline should be consistent with the nature of the unacceptable behavior. At times, however, similar or identical behaviors are met with different disciplinary actions and, in some cases, the cause of the differential action is tied to the personal characteristics of the subordinate. (p. 159)

The need for consistent discipline practices arises from two bases. First, it is important from an equity perspective in terms of treating all employees equally and abiding by relevant laws and collective bargaining agreements (Kearney \& Carnevale, 2001). Second, arbitrary discipline can lead to a demoralized workforce and a loss of productivity (Ban, 1995). Assuming that fair and consistent disciplinary activity is valued by organizations, then discovery of the factors that cause supervisors to respond differently to similar situations is a valuable activity.

This case study presents qualitative findings from four organizations in Puerto Rico. The results, although not generalizable in a statistical sense, offer insight into the utility of existing employee discipline literature and provide a foundation for deductive testing of the factors that influence the 
selection of a disciplinary strategy. Using the native perspective of first-line supervisors, factors such as organization sector, union presence, managerial and the human resource department (HRD) support, and training emerged as explanations. Results from this research suggest that the presence of a union encourages the use of formal discipline strategies. When combined with management and HRD support, and clear policies reinforced by supervisory training, the likelihood of utilization of formal strategies is even higher.

\section{LITERATURE REVIEW}

Employee discipline is an essential activity within all organizations. It is not only useful in preventing, controlling, and changing employees' behaviors but also in attaining organizational goals in more efficient, effective, and productive ways. Disciplinary problems can mean lost productivity, as well as reduced employee morale. Research examining the management of employee discipline is scarce. As Gaertner and Gaertner (1984) observed,

Much research has been directed to the proper application sequence of disciplinary sanctions, the formal requirements to be met, remedial actions to be undertaken, and so on. Implicitly, the aim is to find or create a set of managerial actions that are generally effective at changing employee behavior. The literature suggests variables that can impact the choice of disciplinary strategies. Primary among these are the sector; union presence; and relationships with management and the HRD. (p. 13)

One of the most controversial issues in the management literature concerns whether differences exist between the public and private sectors. Many authors acknowledge differences between sectors. Scott, Ingram, Vitanza, and Smith (2000, p. 412) explained that "managing poor performance in a business environment where expectations are high and staffing is tight can be a lesson in futility." Pollitt and Bouckaert (2000, pp. 15-16) noted, "The relationship between public management and generic management is a contested one." They conclude that there has been extensive borrowing of ideas from the private sector, but public management is a unique and separate field. All organizations face vast pressures to increase productivity and efficiency. There are, however, some basic factors that differentiate public and private organizations. For instance, private organizations enjoy a great deal of discretion and flexibility in operating their enterprises in ways deemed most appropriate to overall organizational interests. 
In contrast, public organizations do not possess such freedoms. Government agencies must consider many interests and then shape policies and procedures to satisfy a wide array of diverse and sometimes conflicting interests. Concerning human resource matters, differences between sectors also exist. In the public sector, personnel management is highly regulated by civil service rules and regulations, whereas in the private sector such regulations do not apply.

The presence of unions can also constrain the actions of the supervisor. Labor contracts impose limitations on the personnel activities of supervisors. Collective bargaining agreements often provide additional layers of protection against arbitrary discipline practices (Katz \& Kochan, 2000).

Supervisors' discretion and authority can also be affected by relationships with their managers and the HRD. Ban (1995, p. 181) found that managers "are likely to go through the lengthy and complex formal process only if they have strong support from their superiors (sometimes several layers up) and from the employee relations staff." The literature suggests that supervisors perceive organizations as nonsupportive when complex disciplinary problems are involved. Imundo (1985, pp. 5-6) points out that "it is not unusual for decisions made by supervisors to be overruled at higher levels of management or by staff specialists."

A lack of training in problem employee management may also limit firstline supervisors' effectiveness in handling disciplinary problems. When appointed, supervisors often receive either no training or training that is highly superficial in nature and not designed to teach them how to handle the difficulties usually associated with disciplinary cases (Ban, 1995; Navy Personnel Research and Development Center, 1984). Robisch (1996) suggested that inadequately trained supervisors have more problems in dealing with poor performers. Training is important because it can provide an opportunity for modeling behavior (learning by imitation). Aufrecht (1996) argued that behavior is strongly influenced through modeling and suggested that to maximize approach (rather than avoidance) tendencies in workers, managers must exhibit those behaviors themselves.

\section{RESEARCH METHOD}

Through a case study approach, this article explores and describes firstline supervisors' choice of discipline strategies. Four Puerto Rican organizations were purposively selected for this study in order to examine differ- 
ences between the private and public sectors and to isolate the impact of a union. Thus, two small, private sector organizations (identified here for reasons of anonymity as Pharmacy and Soda) and two large public sector organizations, the Puerto Rico Telephone Company (PRTC) and the Department of Family and Social Services (DFSS), hereinafter referred to as Telephone and Social Services, respectively, were examined.

Soda and Telephone have unions covering a portion of their employees. In Puerto Rico, the percentage of unionized employees within the private sector is very low. Available estimates suggest that less than $6 \%$ of this workforce is represented by labor unions (Suarez, 1991). In contrast, the percentage of unionized employees within the public sector stands at about $32 \%$. At the time of the study, only Telephone's employees (as members of a public entity) were allowed full unionization rights, including the right to strike.

An equal number of interviews were to be conducted in each of the four organizations. As one company had only 13 first-line supervisors, 13 supervisors from each of the other organizations were randomly selected for inclusion in the research. This was done to avoid overrepresentation of one organization in the results. Forty-two interviews were conducted, for an $81 \%$ response rate. The primary data collection technique was a face-toface ethnographic interview lasting between 2 and 4 hours (Spradley, 1979). During the interviews, each supervisor was asked open-ended questions about employee problems, discipline strategies, and interactions with others inside and outside the organization. The researchers provided clarifying information describing what was meant by concepts such as discipline, management support, and the HRD to assure that interviewees were talking about the same things in their responses. The interview protocol also included questions regarding supervisors' use of formal disciplinary activities such as counseling, verbal and written warnings, suspensions, and terminations. They were also invited to describe any other actions they had taken when confronted with problem employees. These were actions falling outside the formal discipline policy and were labeled by the researchers as informal strategies. This included such things as work reassignment, transfers, and tolerating poor performance. The interview questions were designed to elicit the native perspective on typical disciplinary problems and employee discipline strategies (Geertz, 1973). The value of this qualitative approach lies in the discovery of factors that are highly important to practitioners. Even though the results cannot be treated as reliable or valid 
in any statistical sense, they can serve to empirically confirm existing theories and point out gaps or inconsistencies in our knowledge.

\section{Pharmacy}

Pharmacy is a small (260 employees), nonunionized, manufacturingoriented, private sector organization devoted to packaging and shipping medical products. The operating structure is flat and decentralized, with only four organizational levels. The plant's working environment is familial and informal, as evidenced by the "beer and chips" bashes held for all employees on the first Friday of each month. At Pharmacy, employee participation, a teamwork orientation, and upper-level management access were encouraged. Labor-management relations between supervisors and employees at Pharmacy were not adversarial in nature, as one supervisor described: "I have a dual role of managing and interacting with employees. I am a coach and a guide at the same time." This was viewed as helping the organization remain nonunionized.

The relationship between the first-line supervisors and management was characterized as one of trust, with a large degree of autonomy and discretion granted to the first-line supervisors. As one supervisor observed:

You have freedom to make recommendations, freedom to go to any [managerial] level and present problems or concerns without fear of reprisal. I have the freedom to do, the freedom to create, and the freedom to differ in a responsible way.

The HRD was used by supervisors as their primary source of information when dealing with discipline problems (although first-line supervisors believe they have enough discretion to take any action they deem appropriate). For instance, one supervisor pointed out that "of course I have enough discretion and sufficient authority for making all those decisions which are important to the company." Informally, supervisors turned to their peers, either internal $(55 \%$ noted) or external $(18 \%$ - when supervisors felt a need to protect their professional image), to gain advice based on previous actions. At Pharmacy there were no procedures in place for grievance or arbitration.

Managerial training at Pharmacy was described as seldom offered, despite a fully operational training division within the HRD. A supervisor reported that management training "is not part of the core curriculum." 
Disciplinary problems such as tardiness, absenteeism, and violations of operational rules and procedures were encountered by supervisors at Pharmacy. Personality and other related disorders such as alcoholism, poor interpersonal relationships with coworkers, insubordination, stealing, and drug usage in the workplace were also mentioned as problems, although these were cited less frequently. The detailed human resources manual contains information and guidance describing the verbal and written warnings ( $72 \%$ of Pharmacy's supervisors did this) that must be issued before harsher sanctions can be imposed. The manual encourages supervisors to give employees opportunities to change or improve their behavior.

Pharmacy supervisors used a participative style of management that accommodated the formal policies and also informal strategies. One supervisor explained how he dealt with a performance problem:

The steps I usually follow when I have to handle a problem is to meet with the employee on a weekly basis and try to identify areas for improvement through counseling, and also I start to document the situation from the very beginning.

Fifty-five percent reported tolerating problem behaviors. Many supervisors felt that being flexible was more important than taking formal disciplinary action. Eighteen percent of Pharmacy supervisors reassigned work to employees whose behavior was a result of personal problems. To summarize, the operating environment at Pharmacy was informal with a high emphasis placed on productivity. This point is reinforced by this comment: "What we need is to be flexible; as a supervisor I'm more interested in productivity rather than measuring time." In response, supervisors used a mix of formal and informal strategies to maintain productivity.

\section{Soda}

Soda is a small (210 employees), unionized, manufacturing-oriented, private sector organization, devoted to packaging and delivering raw materials for making beverages. The plant's structure is flat and decentralized, with only four organizational levels. A team orientation and participative working environment was encouraged. Labor-management relations were cordial, described repeatedly as equal, honest, and sincere. However, Soda supervisors "operate by the book" due, in part, to the collective bargaining agreement. 
Both the employee manual and the collective bargaining agreement emphasized the need for impartiality and equity in the treatment of problem employees. Supervisors suggested that they are both familiar with and comfortable in following the guidelines in the two documents and had an active voice throughout the discipline process. A supervisor explained that

There's a collective bargaining agreement where you have a lot of information which you can use. When there's not too much information [on a particular situation] you consult the book (the collective bargaining agreement), and then you look up the article, the page, and [if] still you were not sure enough, there are enough people around with whom you can consult.

On discipline issues, supervisors were given enough flexibility, authority, and discretion by both management and the HRD, as long as their actions were in line with corporate policies and the collective bargaining agreement. The HRD was the primary source of information in selecting a particular discipline strategy. As one supervisor remarked:

The relations between the HRD and the plant, I think, are very good in terms of the support they give us when making disciplinary decisions.... We are all involved in the process and certainly do make recommendations. As far as I'm concerned, they've always been open to hearing what I have to say because I'm the one involved [with employees] on a daily basis.

Supervisors also constantly interacted with the union regarding discipline problems to resolve problems quickly. Additionally, 43\% reported consulting with peers inside the organization. Supervisors often had to wait for training after promotion or hire. When training was finally provided, most found it to be a very useful tool.

Disciplinary problems were typically related to behavior at work such as alcoholism, poor performance of duties, and violation of company rules and procedures. Soda supervisors tended to follow the organization's formal discipline policies. All supervisors issued verbal and written warnings before formal disciplinary sanction. Seventy-one percent also applied harsher sanctions, such as suspension or termination. At times, informal strategies, such as avoiding the labor union $(57 \%)$ or work reassignments $(14 \%)$, were used. When asked about avoiding the labor union, one supervisor offered this explanation:

We [supervisors] try to avoid, no matter what, the intervention of the union delegate or one of the union representatives. We want to solve problems by 
ourselves ... [after a long pause to think] because it is us supervisors [who are] the ones responsible for solving them. When the union intervenes, it's because the supervisor hasn't done his or her job properly. It's as simple as that! If I allow the delegate to solve the problem, then it goes completely out of my hands. I just can't even allow the company to think that each time there's a problem, it's the union delegate, and not me, that is responsible for solving it. That's my responsibility.

As these comments suggest, discipline at Soda was the responsibility of the supervisor. This was made easier by the fact that management and the HRD support their actions. In addition, the clear policies and supervisor's knowledge of the collective bargaining agreement supported managing by the book.

\section{PRTC (Telephone)}

Telephone is a large (7,971 employees), heavily unionized, serviceoriented, public sector corporation. The organization is highly complex and hierarchical in nature, with a structure arranged in many managerial layers. As one supervisor described it, Telephone is "a company that has grown and grown. And, at the same time, it has become more complex, too complex." The operating environment, characterized as having strict rules and a heavy reliance on standard operating procedures, created a restraining working environment for supervisors at this company. Labor-management relations were not adversarial in nature and can best be described as supportive, with participation and teamwork strongly encouraged. Eighty-two percent of employees at Telephone participated in a union. ${ }^{1}$

If a supervisor perceived an employee-related problem, Telephone required counseling, then a written reprimand and suspension after consulting the HRD. Formal policies contained explicit guidance concerning the identification and categorization of employee offenses. A pocket-sized field guide containing the policies as well as the collective bargaining agreement is provided to each supervisor. This was very valuable to first-line supervisors, as one interviewee noted:

The procedures we must follow are clearly detailed in the manual, because if you have a problem, a particular situation, it tells you what to do, and if the situation persists, it would tell you "o.k., now this is what you have to do now." 
Another supervisor indicated that [the PRTC disciplinary manual] "is very organized and useful. You can use it as a guide because it's clear enough. You then evaluate [a disciplinary problem] according to the type of offense."

Management and the HRD were always accessible, interested, and supportive, providing communication and encouragement. One supervisor described them as the "arbitrators and negotiators. They tend to look for a balance. They tended to protect both the employee and the supervisor." The union was also a key player in discipline issues. Some supervisors saw them as a partner in the disciplinary process. Others complained that the labor union was

there in order to make sure they [unionized employees] are not abused by management. ... They try to do whatever they can to avoid getting one of their employees suspended. They grab the evidence at hand and try to negotiate a much less or more lenient sanction.

Beyond their managers, the HRD, and the union, 55\% of supervisors reported consulting internal peers for advice.

Supervisory training was provided in-house almost immediately upon appointment and continued on a regular basis. Though the training was described as focusing more on theory than practice, the training sessions were described as useful. According to one interviewee:

I was appointed [as a supervisor] on a Friday. The very next Monday, I was sent to [Telephone's] managerial development school to attend training. ... It was very useful. For me, it was an eye-opening experience, especially since prior to becoming a supervisor, I was a unionized employee. It helped me a lot ... to clarify many issues, many problems. I learned a lot.

Telephone's supervisors described problems such as absenteeism and tardiness, as well as issues related to poor performance of duties. They tended to follow formal guidelines (83\% indicated knowledge of, comfort with, and adherence to the discipline procedures outlined in the employee manual.) Eighty-three percent had issued written warnings and 50\% had used suspensions. Supervisors did mention informal strategies such as "looking the other way" (33\%), transferring employees (25\%), or even bullying poor performers (17\%). Nonetheless, the vast majority of interviewees reported using formal methods of discipline. From one supervisor's perspective: "I just follow the rules and procedures that are in place. Keep in mind I don't have the power to either transfer an employee or things like that." This reli- 
ance on formal strategies was not surprising given a restraining work environment and heavy emphasis on formal policies and training that explains and reinforces those policies.

\section{DFSS (Social Services)}

Social Services is a large (9,800 employees), nonunionized, serviceoriented, public sector organization. The organization structure is tall and highly complex (or labyrinth-like), with a myriad of managerial layers. One supervisor described it as "a place where processes are slow. They aren't fast enough. They aren't facilitated, probably because of the hierarchical structure and arrangement of the agency." The operating environment can be best described as cordial but conflictive. Interviewees perceived that participatory management and a teamwork orientation were strongly discouraged. However, all interviewees were extremely identified with an agency that protects society's disadvantaged.

Supervisors characterized management and the HRD both as slow to respond and inaccessible. Management was perceived as a hindrance because they rarely shared information and were always more interested in processes than in results when handling employee discipline issues. The HRD rarely made an effort to disseminate the information in the employee manual. It was described as a "paper-pushing, red-tape type of division." In the words of one supervisor,

One of the most serious problems we've had in this agency is the Personnel Office. ... it has spent all its time and energies in filling out paper forms rather than in orienting or training new hires adequately, especially us supervisors.

First-line supervisors preferred not to consult with this office. Instead, 92\% indicated they relied on internal peer consultation. As one supervisor noted: "This department is confused, anxious and disorganized. ... There's a lack of communication at all levels, so I have learned many things by watching others, by observing others, and by asking other supervisors around."

Training was offered infrequently and inconsistently. In some cases an employee initiated the training request, sometimes even paying for it personally. When offered, the training was criticized for lacking utility. The situation was best explained by this quote: 
The agency doesn't support you, nor does it give you the much-needed tools to deal with problems when managing. They don't train you, nor are they interested at all in doing so ... and if they do, training is extremely utopian in nature. They [trainers] spend a lot of time talking about empowerment, better decision-making techniques and so on. But the working environment is a different thing because it doesn't adjust to the realistic nature of such processes.

Supervisors at Social Services also cited absenteeism and tardiness as issues with which they must deal. These problems, plus wasting time, are perceived as chronic discipline issues. The employee manual requires a supervisory conference before written warnings or suspension. Managers have final decision-making authority. In practice, disciplinary actions are often a long and tedious process, in part because supervisors are not familiar with the organization's policies and procedures. In fact, there were some supervisors who openly recognized they did not know where to look for the personnel procedures even though they had dealt with disciplinary problems previously.

In line with the agency mission, the supervisors more frequently tried to solve the employee problem rather than to take formal disciplinary actions. The supervisory conference was the most common formal approach to discipline. Only $50 \%$ of the supervisors interviewed had issued a written warning; $42 \%$ docked the employee's pay. Not one supervisor in this agency had suspended, demoted, or fired an employee, despite the sometimes severe nature of the problems encountered (including stealing government funds). If reprimands were issued they rarely got to the employee's official personnel record. The most common informal strategy was inaction and tolerance of disciplinary problems (83\%), unless the employee had a "pedigree" (a previous and substantially recorded disciplinary history). Other informal strategies (used by $42 \%$ of supervisors) included transferring or bartering "lemons," or creating a "dandy's desk" (not assigning enough work to and also isolating the problem employee). As one supervisor put it:

We have transferred people without asking [other departments] for someone in exchange. What really happens and takes place here at DFSS is that the other directors and supervisors tell you they have someone they want to transfer, they go ahead with the transfer, and then what you receive instead are lemons. I don't think that's right. Personally, if I'm having a similar problem, I usually talk to other supervisors and let them know beforehand the kind of employee they will get if I do transfer someone. 
Based on interviewee comments, Social Services is a large, bureaucratic structure that is inaccessible and slow to respond, which, when combined with the desire to protect the disadvantaged employee, results in a heavy reliance on informal strategies. Formal actions, when taken, may not be supported by management or the HRD, so many supervisors elect to tolerate poor performers (or engage in other informal strategies).

\section{FINDINGS AND DISCUSSION}

Across the organizations studied, supervisors face similar discipline problems: tardiness, absenteeism, personal problems, or poor performance of duties. Each organization had a formal discipline system suggesting progressive discipline that includes a counseling session. Generally speaking, supervisors attempted to use the formal discipline methods (except for those at Social Services). Pharmacy supervisors were the most consistent in applying formal strategies, and Social Service supervisors were among the most inconsistent (and lenient).

Informal strategies are also evident in the organizations, but to a differing extent. Supervisors in every organization reported avoidance or tolerance as a disciplinary strategy. This strategy was prevalent enough, in some organizations, to warrant attention, ranging from a low of $27 \%$ of supervisors in Pharmacy to a high of $83 \%$ of supervisors in Social Services. The native explanations concerning why formal or informal strategies are selected are considered below.

The organizations in this study were selected purposively to examine differences based on sector and unionization. Supervisors in Telephone (public) and Soda (private) reported using formal disciplinary strategies. In the other private organization (Pharmacy), the supervisors used a mix of formal and informal strategies. Supervisors at Social Services, where there are civil service rules and regulations, avoided the formal disciplinary process as a standard practice. Overall, sector does not provide a very robust explanation in the variation in discipline strategies.

In contrast, the presence of a union is an important explanatory factor. Supervisors in the unionized organizations (Soda and Telephone) relied extensively on formal strategies. The results suggest that although labor unions, at times, complicate supervisory tasks, they also influence supervisors to approach discipline more formally and consistently and to emphasize equity, fairness, and due process. For Soda the relationship with the 
union was described as "by the book." At Telephone the relationship was characterized as supportive. Even though the union relationship was described differently at each organization, there was no noticeable difference in the supervisor's disciplinary strategies. In both organizations formal discipline was preferred.

There are other factors that interviewees considered when choosing a discipline strategy. First among these was the perceived level of management support. When supervisors felt they had the support of management, not only were they more willing to address discipline in a timely fashion but they were also more willing to use formal, instead of informal, discipline strategies. The reverse held true, as can be seen in Social Services, where a lack of communication existed and management was perceived as inaccessible. For this organization the more informal approach to discipline was dominant.

The HRD also had substantial influence-either positive or negativeon the strategies taken by its supervisors. In the two private organizations (Soda and Pharmacy), some supervisors felt the HRD was supportive and likened this unit to a close partner or facilitator. However, managing discipline in these two organizations was somewhat different. Supervisors at Soda relied on formal strategies, whereas Pharmacy supervisors used a mix of formal and informal disciplinary strategies. At Social Services, where the HRD was viewed as a bureaucratic or nonsupportive department, there was more of a reliance on informal strategies.

If there was an organizational emphasis on training, then the supervisor was more likely to understand and use formal disciplinary approaches. The unionized organizations (Telephone and Soda) tended not only to be more systematic in offering training but also to present information deemed to be useful, unlike their nonunionized counterparts. Telephone supervisors attributed timely and useful training to helping them manage discipline using formal strategies. In Pharmacy, where training was seldom offered, the disciplinary approach was mixed. For Soda, where training was slow in coming but when finally offered, useful, the disciplinary approach was for$\mathrm{mal}$. And at Social Services, where training was infrequent, supervisors were the most creative in developing informal strategies.

The variance in the choice of formal or informal strategies can be better understood by examining the interaction of certain factors. This research suggests a relationship between supervisor's behaviors and the combined signals an organization emits regarding the treatment of disciplinary problems. Compliance with formal disciplinary policy was closely related to the degree to which the organization supported its supervisors. When support 
is present from management, the $\mathrm{HRD}$, and the union, then supervisors are more likely to follow formal discipline policies. It appears to be a combination of the clarity of and accessibility to formal policies, combined with ongoing reinforcement from key organization officials, that supports formal discipline actions.

It is also striking that the unionized organizations, perhaps spurred by the collective bargaining process, had the clearest and most usable discipline policies. These organizations also put forth the most effort to train their employees and actively continue to work with first-line supervisors through supportive relationships with managers and the HRD. Telephone is the best example of the importance of the combination of these factors (but conditions are very similar at Soda as well). The supervisors' pocketsized rulebook, along with immediate and constant training and supportive interactions with management, the HRD, and the union, encouraged supervisors to handle employee discipline more formally. As further support, when faced with a particular problem only half of the supervisors at Telephone turned to their peers (as opposed to management or the HRD), and less than one third described informal strategies such as tolerating the problem or transferring the problem employee.

In contrast, in Social Services supervisors spent a great deal of their time circumventing problems rather than disciplining employees. The many constraints they constantly faced help explain why disciplinary actions were avoided. First and foremost, the policies and procedures were unclear. Most supervisors did not know where these items were and never referenced them. Furthermore, managers were described as inaccessible and the HRD as too bureaucratic and slanted to protecting the employee. Recall that $92 \%$ of Social Services supervisors reported contacting their peers first when confronted with a disciplinary issue. Even when peer consultation occurred, supervisors handled discipline inconsistently and informally. It appears that supervisors approached the discipline of each individual employee differently depending on the employee's history as well as the current problem with which they were confronted, reflecting the lack of organizational support.

\section{CONCLUDING COMMENTS}

Although the literature describes a variety of steps for supervisors to take when dealing with disciplinary problems, supervisors tailor the strategies they employ according to a number of factors. No two discipline cases are 
the same. Supervisors devise strategies on a case-by-case basis based on both the specifics of the situation and the employee's pedigree (history). One conclusion that emerges from this research is that structural factors take precedence in influencing supervisors' behaviors on whether to use formal or informal strategies when managing disciplinary issues. The presence of labor unions and a detailed collective bargaining agreement, along with clear rules and procedures and the training supervisors receive, make supervisors more inclined to follow formal strategies when dealing with disciplinary issues. This results in a more consistent approach to discipline. Managing discipline "by the book," then, becomes the way supervisors in these organizations handled problems.

Another finding to emerge from this study is that the amount of time supervisors devoted to peer consultation (either internal and/or external peers) when confronted with disciplinary problems is significant. It is suggested that this occurs when management and the HRD support are absent. Although this may jeopardize organizational efforts to manage employee discipline in a consistent fashion, when used in conjunction with more formal procedures it may actually help supervisors in general, and the organization in particular, to deal with disciplinary problems more practically. The effects of peer consultation warrant further investigation.

Certainly there may be other factors that are equally or more important in terms of explaining variance in employee discipline. The factors presented here emerged from the supervisors' perspective of what is important when choosing a disciplinary strategy. Documenting the variety of strategies used is a valuable contribution and outweighs the limitations of a small, nonrandom sample. Though not generalizable, the findings suggest factors that can be deductively tested in future research. For example, if management and HRD support are as important as the supervisors in our study indicate, then organizations can proactively consider how to promote supportive interactions through structural changes and enhanced communication patterns. Organizations could use those findings to assess the degree to which there is consistency in key structural factors and, based on that assessment, take strategic action to assure that first-line supervisors receive clear and consistent signals regarding appropriate disciplinary strategies.

\section{NOTE}

1. After data collection the Puerto Rican government announced an agreement to sell a controlling interest in Telephone to GTE, now Verizon. 


\section{REFERENCES}

Aufrecht, S. E. (1996.) Toward a model for determining appropriate corrective action in public employee discipline. Journal of Collective Negotiations in the Public Sector, 25(3), 171-198.

Ban, C. (1995). How do public managers manage? Bureaucratic constraints, organizational culture, and the potential for reform. San Francisco: Jossey-Bass.

Bellizzi, J. A., \& Hasty, R. W. (2000). The effects of hiring decisions on the level of discipline used in response to poor performance. Management Decision, 38(3), 154-159.

Gaertner, G. H., \& Gaertner, K. N. (1984). Formal disciplinary actions in two federal agencies. Review of Public Personnel Administration, 5(1), 12-24.

Geertz, C. (1973). The interpretation of cultures. New York: Basic Books.

Imundo, L. V. (1985). Employee discipline: How to do it right. Belmont, CA: Wadsworth.

Katz, H. C., \& Kochan, T. A. (2000). An introduction to collective bargaining and industrial relations. New York: McGraw-Hill.

Kearney, R. C., \& Carnevale, D. G. (2001). Labor relations in the public sector (3rd ed.). New York: Marcel Dekker.

Navy Personnel Research and Development Center. (1984). The first-line supervisor: Literature review (MPRDC TR 84-18). San Diego, CA: U. S. Navy.

Pollitt, C., \& Bouckaert, G. (2000.) Public management reform: A comparative analysis. New York: Oxford University Press.

Robisch, T. G. (1996). The reluctance of federal managers to utilize formal procedures for poorly-performing employees. Review of Public Personnel Administration, 16(2), 73-85.

Scott, K. J., Ingram, K. M., Vitanza, S. A., \& Smith, N. G. (2000). Training in supervision: A survey of current practices. The Counseling Psychologist, 28(3), 403-422.

Spradley, J. P. (1979). The ethnographic interview. Dallas, TX: Holt, Rinehart \& Winston.

Suarez, L. A. (1991, April). Organización sindical en Puerto Rico en la decada de los '90s [Labor organizing in Puerto Rico during the '90s]. Paper presented at the Sixth Labor Conference, Dearborn, MI.

JAVIER F. PAGAN is an assistant professor in the College of Business Administration of the University of Puerto Rico. He teaches courses in management, human resource management, and organizational behavior. He also teaches public personnel management at the Graduate School of Public Administration. His research interests focus on labor-management relations and human resource practices within public and private sector organizations.

AIMEE L. FRANKLIN is an assistant professor at the University of Oklahoma. Her research and teaching focuses on improving public management, with areas of interest in strategic planning, budgeting, evaluation, performance measurement, and ethics. 